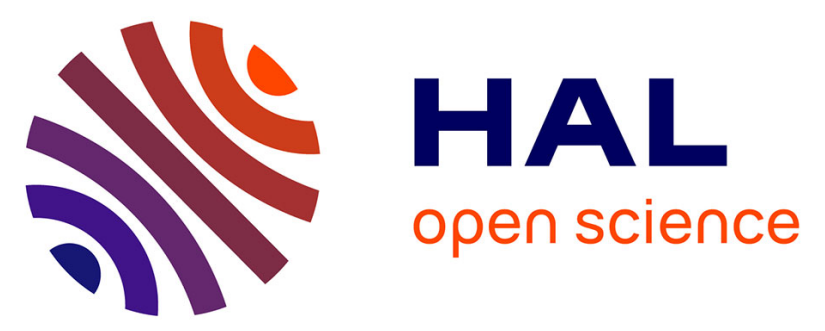

\title{
InGaN/InGaN multiple-quantum-well grown on InGaN/GaN semi-bulk buffer for blue to cyan emission with improved optical emission and efficiency droop
}

Saiful Alam, Suresh Sundaram, Miryam Elouneg-Jamroz, Xin Li, Youssef El Gmili, Ivan Christophe Robin, Paul B Voss, Jean-Paul Salvestrini, Abdallah

Ougazzaden

\section{To cite this version:}

Saiful Alam, Suresh Sundaram, Miryam Elouneg-Jamroz, Xin Li, Youssef El Gmili, et al.. InGaN/InGaN multiple-quantum-well grown on InGaN/GaN semi-bulk buffer for blue to cyan emission with improved optical emission and efficiency droop. Superlattices and Microstructures, 2017, 104, pp.291-297. 10.1016/j.spmi.2017.02.036 . hal-01830907

\section{HAL Id: hal-01830907 https://hal.science/hal-01830907}

Submitted on 2 Mar 2022

HAL is a multi-disciplinary open access archive for the deposit and dissemination of scientific research documents, whether they are published or not. The documents may come from teaching and research institutions in France or abroad, or from public or private research centers.
L'archive ouverte pluridisciplinaire HAL, est destinée au dépôt et à la diffusion de documents scientifiques de niveau recherche, publiés ou non, émanant des établissements d'enseignement et de recherche français ou étrangers, des laboratoires publics ou privés.

\section{(1) (1) $\$$}

Distributed under a Creative Commons Attribution - NonCommercial - NoDerivatives 44.0 


\title{
InGaN/InGaN multiple-quantum-well grown on InGaN/GaN semi-bulk buffer for blue to cyan emission with improved optical emission and efficiency droop
}

\author{
Saiful Alam ${ }^{\mathrm{a}, \mathrm{b}, \mathrm{c}}$, Suresh Sundaram ${ }^{\mathrm{b}}$, Miryam Elouneg-Jamroz ${ }^{\mathrm{c}}, \mathrm{Xin}_{1 \mathrm{i}}^{\mathrm{b}}$, Youssef El \\ Gmili $^{\mathrm{b}}$, Ivan Christophe Robin ${ }^{\mathrm{c}}$, Paul L. Voss ${ }^{\mathrm{a}, \mathrm{b}}$, Jean-Paul Salvestrini ${ }^{\mathrm{b}, \mathrm{d}}$, Abdallah \\ Ougazzaden ${ }^{\mathrm{a}, \mathrm{b}^{*}}$
}

${ }^{a}$ School of Electrical and Computer Engineering, Georgia Institute of Technology, Atlanta, Georgia 30332,USA.

${ }^{b}$ Georgia Tech-CNRS, UMI 2958, 57070 Metz, France.

${ }^{c}$ CEA-LETI, Minatec Campus, F-38054 Grenoble, France.

${ }^{d}$ LMOPS, University of Lorraine, EA4423, 57070 Metz, France.

\begin{abstract}
$\mathrm{In}_{0.16} \mathrm{Ga}_{0.84} \mathrm{~N} / \mathrm{In}_{0.05} \mathrm{Ga}_{0.95} \mathrm{~N}$ Multiple Quantum Well (MQW) structure grown on a $70 \mathrm{~nm}$ thick high quality semi-bulk InGaN buffer layer is reported. Temperature dependent photoluminescence (PL) reveals $67.5 \%$ of room temperature Internal Quantum Efficiency (IQE) at an emission peak of $\sim 455 \mathrm{~nm}$ with FWHM of $20 \mathrm{~nm}$. Low temperature PL study shows clear improvement in emission intensity when conventional GaN buffer and $\mathrm{GaN}$ barrier are replaced by semi-bulk InGaN buffer in addition with InGaN barrier. Simulation confirms improved IQE and reduced efficiency droop when using semi-bulk as buffer which is attributed to the improved overlapping of electron-hole wave functions due to the reduced internal electric field from counteraction by surface polarization field. This efficiency improvement is very beneficial for high In content green LEDs where the efficiency is limited by polarization induced Quantum Confined Stark Effect (QCSE) for excess indium content.
\end{abstract}

Keywords: InGaN multi-quantum-well; InGaN buffer; LED; MOVPE

\section{Introduction}

$\mathrm{GaN}$ is one of the most promising materials for fabrication of efficient light emitting devices in the complete visible spectral range [1]. InGaN/GaN based blue light emitting diodes (LEDs) have a fairly good performance now-a-days [2]. However, to compete with conventional lighting, the efficiency is yet to be improved, particularly in the "green-gap" range [3]. For longer wavelengths such as green emission, the

\footnotetext{
* Corresponding author. Tel.: +33 3872039 23; fax: +33 387203940

E-mail address: aougazza@georgiatech-metz.fr.
} 
efficiency of devices grown in the commonly used $+c$ (0001) direction of GaN decreases with increasing indium (In) content in the active region [4]. This phenomenon is attributed to the built-in piezoelectric field in the biaxially compressively strained InGaN MQWs. Such a piezoelectric field leads to a local spatial separation of electrons and holes within the quantum wells (QWs), which is the so called Quantum Confined Stark Effect (QCSE), and consequently leads to a decreased emission efficiency due to a lower recombination probability between electrons and holes [1,4]. Furthermore, polarization field is considered to be one major possible reason of efficiency droop at high current density [5]. Several groups have proposed reduction of polarization field and improvement of optical performance by using semi- or non-polar direction growth [68], asymmetric QWs using AlGaN, InGaN, GaAsN [9-11], staggered QW [12-16], triangular QW [17-19], and using AlInGaN barriers [20]. Moreover, reduction or balance of strain has been suggested by using InGaN barrier [21-23], InGaN pre-layer [24-28] and also using $\operatorname{In}_{\mathrm{x}} \mathrm{Ga}_{1-\mathrm{x}} \mathrm{N} / \mathrm{Al}_{\mathrm{y}} \mathrm{Ga}_{1-\mathrm{y}} \mathrm{N} / \mathrm{GaN} \mathrm{MQW}$ [29,30]; however, internal electric field might need to be sacrificed for improved material quality by strain compensation [29] and realization of a high quality InGaN buffer layer is also very critical, which has been addressed [26,31]. Nevertheless, good crystal quality, requirement of less In content to get same wavelength emission compared to that for semi- or non-polar direction growth [29] and mask free fewer processing steps make +c-direction growth still commercially promising and combined theoretical and experimental study to alleviate polarization field and enhance optical emission regarding this direction growth by optimized structure design are still important. In this article, we report on a new approach of growing high IQE InGaN/InGaN MQWs using a high quality semi-bulk (SB) InGaN buffer (4 periods of $15 \mathrm{~nm} \mathrm{InGaN} \mathrm{and} 2 \mathrm{~nm}$ GaN layers in between two successive InGaN layers) that shows improvement of optical emission and reduction of efficiency droop at an emission wavelength of $\sim 455 \mathrm{~nm}$ and we explain this improvement theoretically by simulation. This semibulk approach for InGaN growth allows to have a high quality thick InGaN buffer compared to bulk InGaN [32], where inserted thin GaN layer between two successive InGaN layers absorbs excess In and helps to avoid phase separation and quality degradation of the final thick InGaN buffer [32].

\section{Experimental section}

\subsection{Growth}

The samples were grown in a T-shape horizontal flow low-pressure metal organic vapor phase epitaxy (MOVPE) reactor [33] on $3.5 \mu \mathrm{m}$ standard n-doped commercial GaN templates (STN) on (0001) direction sapphire substrate. The growth temperature was $795{ }^{\circ} \mathrm{C}$ for $\mathrm{InGaN}$ growth and $1000{ }^{\circ} \mathrm{C}$ for $\mathrm{GaN}$ growth. The reactor pressure was 100 Torr. Nitrogen $\left(\mathrm{N}_{2}\right)$ and Hydrogen $\left(\mathrm{H}_{2}\right)$ were used as carrier gas. Trimethylgallium (TMGa), trimethylindium (TMIn) and ammonia $\left(\mathrm{NH}_{3}\right)$ were employed as precursor sources for $\mathrm{Ga}$, In and elemental N, respectively. The V/III ratio and TMIn precursor flow were calibrated to achieve desired In percentage in InGaN layers. Three sets of MQW structures were grown, named as sample A, B and C. Sample A had $1 \mu \mathrm{m}$ n-GaN on GaN template, followed by $70 \mathrm{~nm}$ nid-GaN buffer and then 3 periods of $5 \mathrm{~nm} \mathrm{GaN}$ barrier and $3 \mathrm{~nm} \mathrm{In}_{0.16} \mathrm{Ga}_{0.84} \mathrm{~N}$ well and finally capped by $2 \mathrm{~nm} \mathrm{GaN}$. Sample B had similar structure, except that the $\mathrm{GaN}$ barriers were replaced by $\mathrm{In}_{0.05} \mathrm{Ga}_{0.95} \mathrm{~N}$. And in sample $\mathrm{C}$ both the GaN buffer and GaN barriers were replaced by $\operatorname{In}_{0.05} \mathrm{Ga}_{0.95} \mathrm{~N}$ semi-bulk (SB) buffer and $\operatorname{In}_{0.05} \mathrm{Ga}_{0.95} \mathrm{~N}$ barriers respectively. The structures are shown in Fig. 1.

\subsection{Characterization}

High-resolution X-ray diffraction (HR-XRD) measurements were performed in a Panalytical X'pert Pro MRD system with $\mathrm{Cu}-\mathrm{K} \alpha$ radiation. XRD reciprocal space maps (RSMs) of the asymmetric (11.4) plane were used to determine degree of relaxation of the InGaN layers. The thickness was measured by growth rate calculated from in-situ reflectrometry and confirmed by transmission electron microscopy (TEM). 


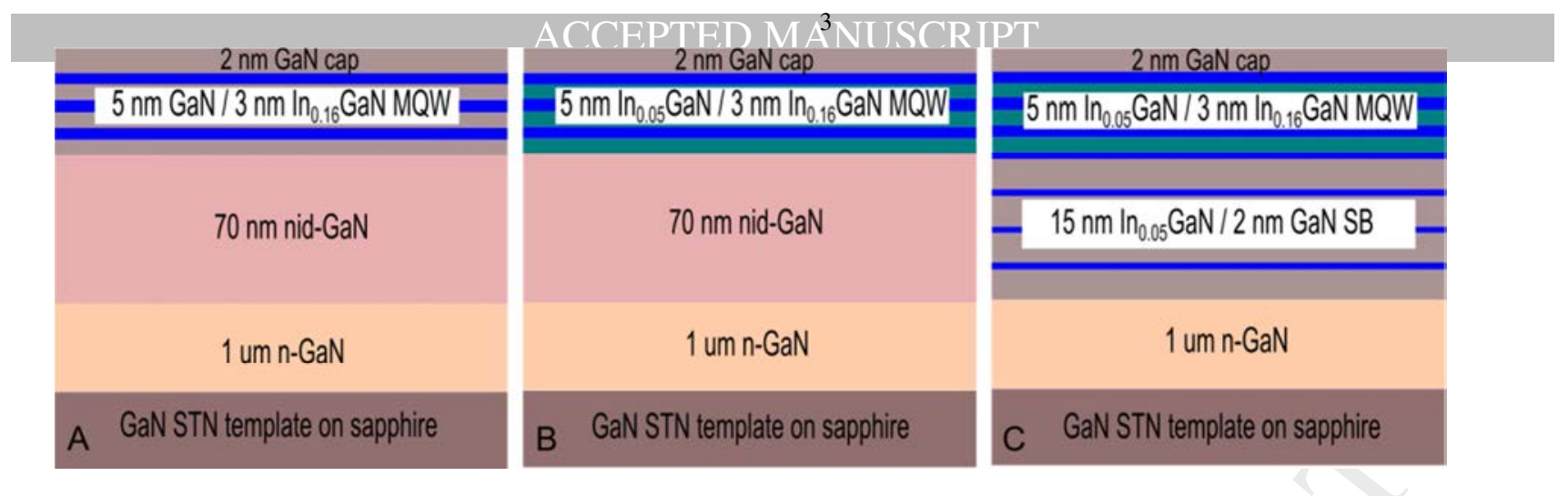

Fig. 1. Structure of the three samples under this study: reference sample A with GaN buffer and GaN barrier, reference sample B with GaN buffer and $\operatorname{In}_{0.05} \mathrm{Ga}_{0.95} \mathrm{~N}$ barrier and final structure of sample $\mathrm{C}$ with semi-bulk $\operatorname{In}_{0.05} \mathrm{Ga}_{0.95} \mathrm{~N}$ buffer and $\operatorname{In}_{0.05} \mathrm{Ga}_{0.95} \mathrm{~N}$ barrier.

The surface morphology was studied by scanning electron microscopy (SEM) and atomic force microscopy (AFM). Optical emission properties of InGaN structures were investigated by both cathodoluminescence (CL) and photoluminescence (PL) measurements. Room-temperature and low temperature CL investigations were performed in a digital scanning electron microscope [34]. Temperature dependent PL spectra were measured in a helium cryostat from $15 \mathrm{~K}$ to $290 \mathrm{~K}$ using a $375 \mathrm{~nm}$ laser as excitation source. The excitation power was varied from 0 to $48 \mathrm{~mW}$ with a beam diameter of roughly $100 \mu \mathrm{m}$. To avoid wafer non-uniformity, similar areas at the center region on the wafers were measured in the PL study carefully at the same time with similar optical conditions to ensure that the results were comparable.

\subsection{Simulation}

The structures were simulated by Silvaco TCAD software, where self-consistent band structures and wave functions were obtained by solving the Schrödinger equation for electrons, Hamiltonian for holes and Poisson's equation iteratively [35]. The drift-diffusion k.p model was used, interface and surface charge and career screening effect were considered and material parameters were taken after Bernardini and Fiorentini et al. [36]. The simulation was carried out for a bias of $50 \mathrm{~A}$ and upto $3.4 \mathrm{~V}$.

\section{Results and discussion}

The growth was optimized to get a $\sim 70 \mathrm{~nm}$ thick good crystal quality SB InGaN buffer. The material and morphological quality of this buffer layer were examined by HR-XRD, SEM and AFM. Fitting the XRD experimental data by simulation gave $5 \pm 1 \%$ In incorporation and reciprocal space mapping (RSM) showed fully strained situation. SEM image (Fig. 2a) showed good surface morphology with V-pit density of $8 \times 10^{6}$ $\mathrm{cm}^{-2}$. Surface roughness of $1.3 \mathrm{~nm}$ for a $5 \mu \mathrm{m} \times 5 \mu \mathrm{m}$ scan area was obtained by AFM for this SB InGaN buffer, much better than that of the bulk InGaN [32]. To ensure the SB quality, room temperature CL was carried out that showed a sharp emission peak at $~ 400 \mathrm{~nm}$ with a FWHM of $22 \mathrm{~nm}$ (Fig. 2b) confirming single phase In, whereas bulk InGaN has multiple emission peaks corresponding to different separated phases [32]. The MQWs with $16 \pm 1 \%$ were grown on top. Fig. 2c shows XRD experimental data for sample A, B and $\mathrm{C}$ which fits well with the simulation of the designed structure. Sample $\mathrm{C}$ had $\sim 15 \%$ relaxation (Fig. 2c, inset) and a surface morphology with V-pit density of $8 \times 10^{7} \mathrm{~cm}^{-2}$, whereas sample A and B were fully strained with V-pit density of $8.5 \times 10^{8} \mathrm{~cm}^{-2}$ and $7.1 \times 10^{8} \mathrm{~cm}^{-2}$ respectively. Using of SB buffer 

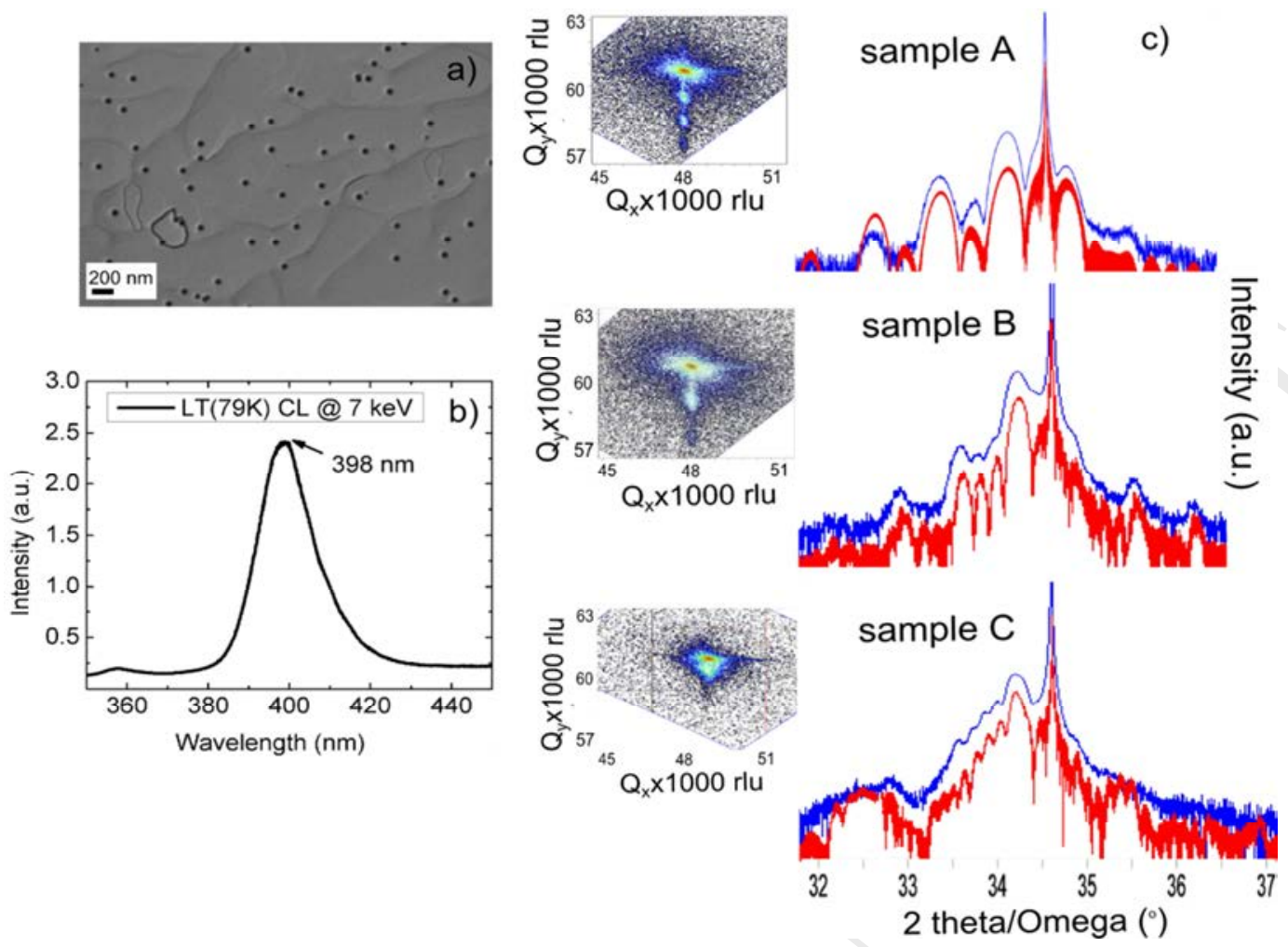

Fig. 2. SEM image of semi-bulk (SB) buffer sample (a), low temperature CL emission of SB buffer (b) and XRD $2 \theta$ - $\omega$ scan of sample A, $\mathrm{B}$ and $\mathrm{C}$ (c) (inset shows the RSMs ).

The rms roughness of sample $\mathrm{C}$ was $1.50 \mathrm{~nm}$ and that of sample A and B were $2.0 \mathrm{~nm}$ and $1.8 \mathrm{~nm}$ respectively from AFM for a $5 \mu \mathrm{m} \times 5 \mu \mathrm{m}$ scan area. Though using SB buffer in sample C increased the size of the V-pits, the less pit density and absence of inclusion defects due to the partial reduction of localized variation of strain energy [37] made the surface morphology comparable. In the low temperature (15 K) PL experiment, sample A showed an emission peak at $490 \mathrm{~nm}$ and sample B showed an emission at $\sim 438 \mathrm{~nm}$ (Fig. 3a). More than three-fold improvement in emission intensity for sample B is attributed to the reduction in potential barrier height and more homogeneous repartition of carriers in the wells for putting indium in the barrier. LTPL for sample C (Fig. 3b) yielded an emission at $\sim 454 \mathrm{~nm}$ with a FWHM of $20 \mathrm{~nm}$. The semi-bulk (SB) peak is also visible at $\sim 405 \mathrm{~nm}$. Even though the internal electric field was reduced in MQW of sample $\mathrm{C}$ compared to that in MQW of sample $\mathrm{B}$, as it will be shown in simulation result later, the $\sim 15 \mathrm{~nm}$ red shift in emission wavelength for sample $\mathrm{C}$ is attributed to the partial strain relaxation related In content variation and slight In pulling induced increase of well thickness. The PL emission intensity, when using the SB InGaN as buffer, got doubled compared to sample B and shows six-fold increment compared to sample A. This improvement was definitely due to the insertion of the SB buffer layer as both sample B and sample C has the same MQW structure except that sample $\mathrm{C}$ has InGaN SB buffer beneath the MQWs. From the measured integrated intensity at different laser excitation power and from $15 \mathrm{~K}$ to $290 \mathrm{~K}$ temperature range and using power normalized integrated intensity, the room temperature IQE was calculated to be $67.5 \%$ by considering the radiative recombination efficiency is $100 \%$ at $15 \mathrm{~K}$ [38]. Fig. $3 \mathrm{~b}$ (inset) shows the integrated PL intensity vs $1 / T$ curve for sample $\mathrm{A}, \mathrm{B}$ and $\mathrm{C}$. It can be seen that the thermal quenching of non-radiative recombination 
process is worse for sample A and B compared to that of sample $\mathrm{C}$ and the shape of these curves suggest that the intensity decrease is more prominent at high temperature range for sample $\mathrm{A}$ and $\mathrm{B}$ than that of sample $\mathrm{C}$ revealing the reduced effect of non-radiative recombination channel for sample C [39].
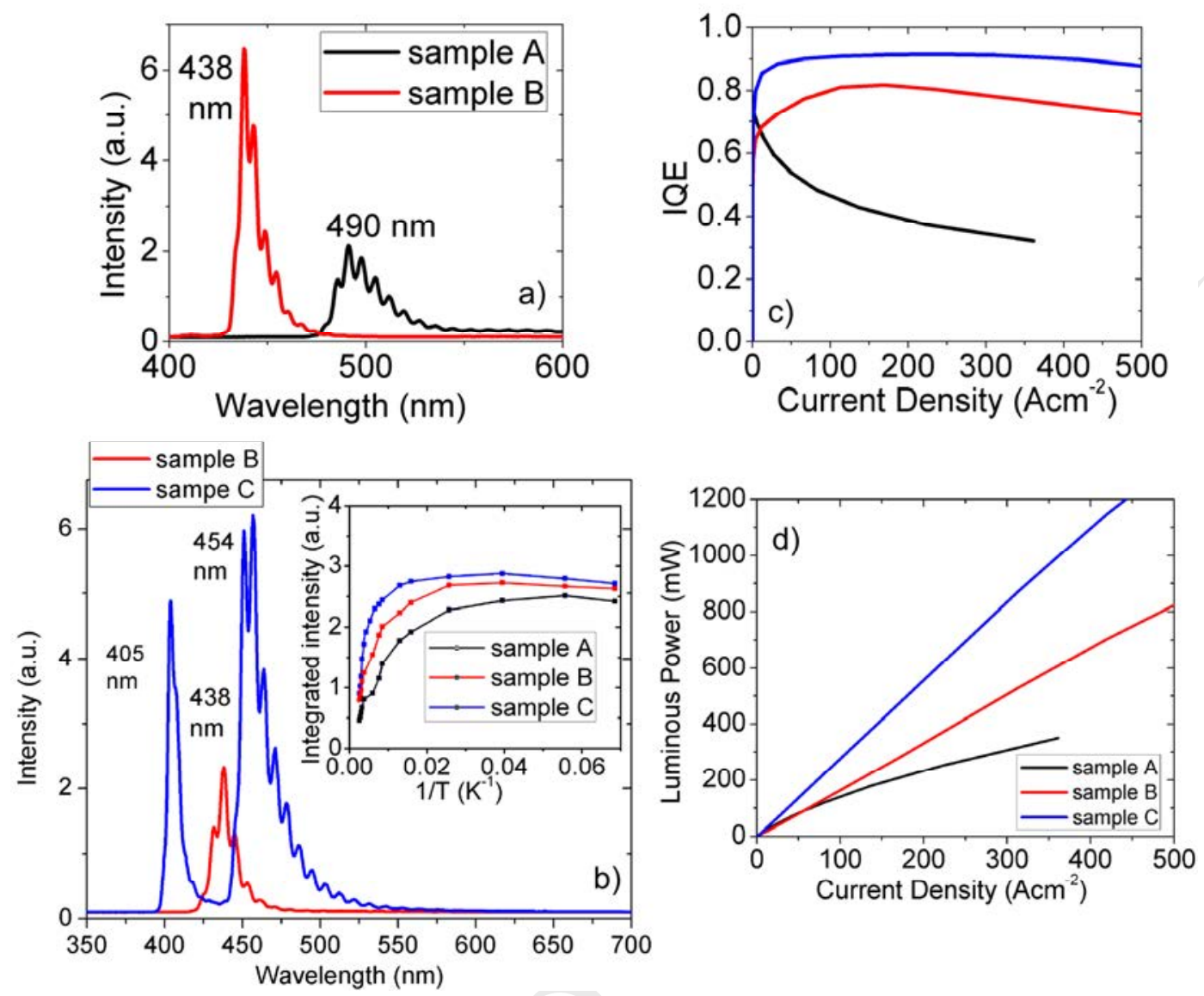

Fig. 3. Low temperature (15 K) PL spectra comparison of sample A and B (a) and sample B and C (b) (inset shows the integral PL intensity versus $1 / T$ for sample C). Calculated IQE (c) and luminous power (d) comparison of sample A, sample B and sample C.

To understand the improved luminescence performance of our final MQW structure sample $\mathrm{C}$, simulation was carried out [35]. At a current density of $200 \mathrm{~A} / \mathrm{cm}^{2}$, a 130\% improvement of room temperature IQE compared to that of sample A and 15\% compared to that of sample B have been obtained (Fig. 3c). Moreover, there was no efficiency droop for sample $\mathrm{C}$ at this current density compared to sample $\mathrm{A}$ and $\mathrm{B}$. The calculated luminous power for sample $\mathrm{C}$ was doubled compared to sample $\mathrm{A}$ and $~ 60 \%$ improved compared to sample $\mathrm{B}$ at this current density (Fig. 3d). This improvement is attributed to the reduction of net electric field in sample C. Using InGaN as a barrier reduced the built-in electric field [40]. Further reduction in the average electric field in the three wells was mainly due to the use of SB InGaN as buffer because the oppositely directed surface charge related field reduced the net built-in electric field [23]. For sample C, 1.5 times less electric filed was calculated compared to sample A and the average electric field in the wells was $0.1 \mathrm{MV} / \mu \mathrm{m}$ less compared to that of sample B (Fig. 4b). The polarization charge concentration was half in the structure with InGaN barrier (sample B) as shown in Fig. 4a compared to that of the reference structure (sample A). The reduction in net electric field when using $\mathrm{SB}$ InGaN as buffer resulted in reduced band bending (Fig. 4c). As a 
result, the QCSE was reduced and there was more overlap of electron and hole wave functions (Fig. 5) for the final structure sample C. In fact, $38.7 \%$ more overlap compared to sample A and $9 \%$ more overlap compared to sample B was obtained.
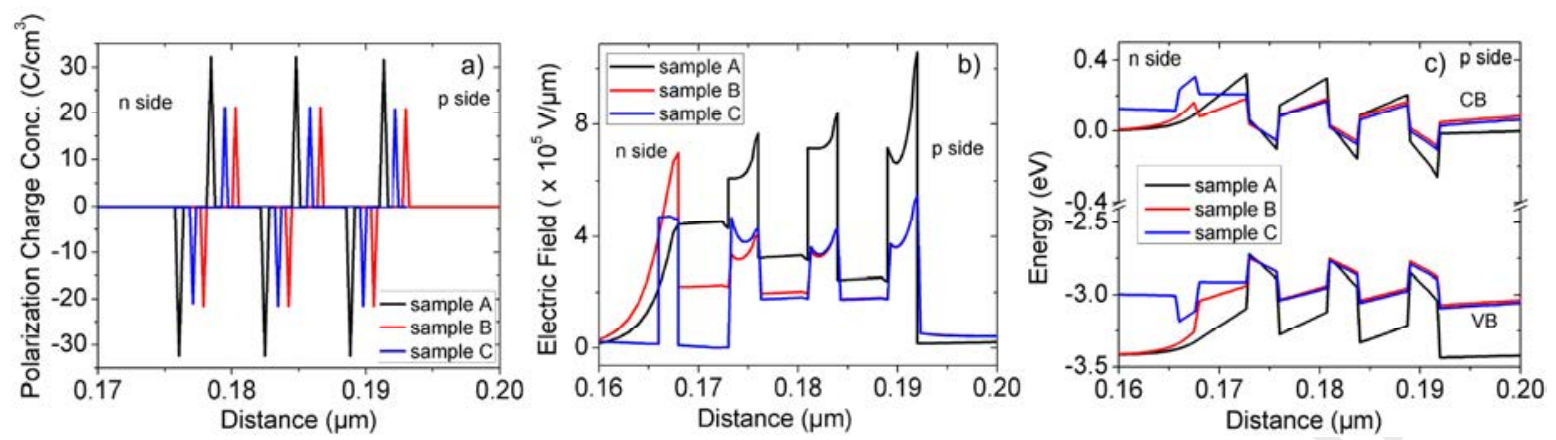

Fig. 4. Polarization charge concentration (a), internal electric field (b) and valence and conduction band structure (c) for the samples under study. Please note that, in (a), the distance scale has been shifted for sample A and B for better visibility.
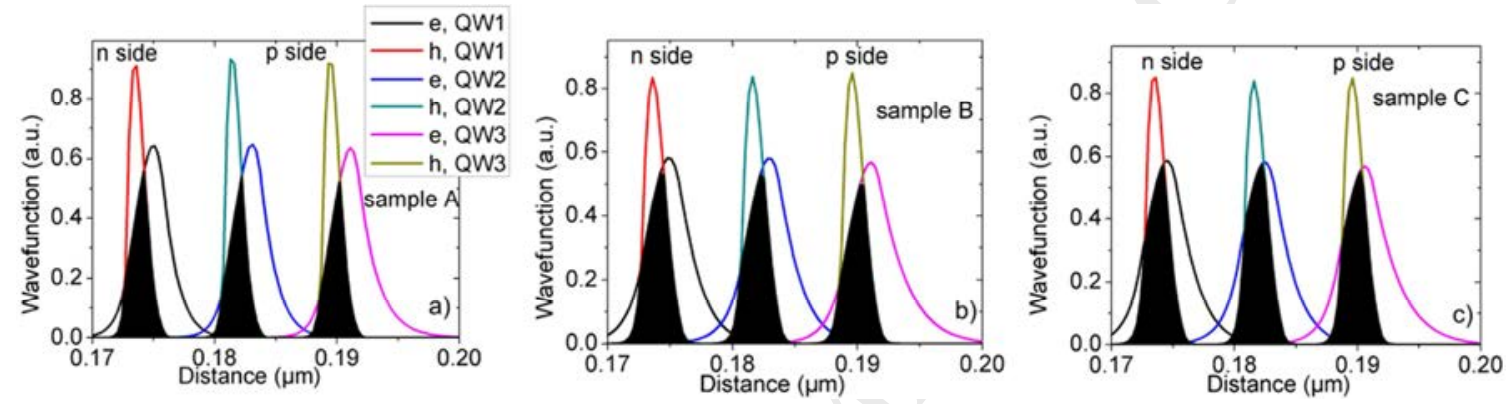

Fig. 5. Electron and hole wavefunction overlap for (a) reference sample A (b) reference sample B and c) our final structure sample C.

This improved overlapping led to more radiative recombination and hence was consistent with the experimental increase of PL emission intensity [25]. For sample C, the spontaneous emission rate and the total radiative recombination rate (not shown here) were also calculated to be higher than that of the reference structures A and B, and was attributed to the reduced electric field [22,27]. This led to more homogenous distribution of carriers [20] in the MQWs grown on SB InGaN buffer and improved tunneling of electrons from the buffer that was un-intentionally n-doped and acted as an electron reservoir. While the design and experiment suggest $5 \pm 1 \%$ In in the SB buffer and in the barrier for the best optical performance from $450 \mathrm{~nm}$ to $480 \mathrm{~nm}$ wavelength range, simulations for longer wavelength suggests scaled up In in the barriers and in the SB InGaN buffer for the best room temperature IQE performance (summarized in table 1).

Optimization of growth parameters to get SB InGaN buffer with higher In content maintaining good crystal quality and realization of MQWs on top for longer wavelength $(\sim 520 \mathrm{~nm})$ emission is the subject of current study. 
Table 1. Simulated emission wavelength and IQE of MQWs with different In content in well and SB buffer.

\begin{tabular}{cccc}
\hline $\begin{array}{c}\text { In (\%) in } \\
\text { well }\end{array}$ & $\begin{array}{c}\text { In (\%) in SB } \\
\text { buffer and } \\
\text { InGaN barrier }\end{array}$ & $\begin{array}{c}\text { Wavelength } \\
(\mathrm{nm})\end{array}$ & $\begin{array}{c}\text { IQE (\%) } \\
\text { @ 200 Acm }\end{array}$ \\
\hline 30 & 15 & 510 & $68 \%$ \\
35 & 20 & 535 & $55 \%$ \\
40 & 25 & 560 & $52 \%$ \\
\hline
\end{tabular}

\section{Conclusion}

In summary, the InGaN MQW with InGaN barrier grown on a $\sim 70 \mathrm{~nm}$ thick fully strained semi-bulk InGaN buffer gave almost double optical emission compared to conventional MQW structure with GaN barrier and $\mathrm{GaN}$ buffer. This improvement is due to the screening of built in field by surface polarization field that eventually reduced the net built-in electric field in the wells and also due to more homogenous carrier distribution among the MQWs, when grown on semi-bulk InGaN buffer. These effects resulted in reduced band bending that increased the emission efficiency by more overlapping of electron and hole wave functions. $67.5 \%$ internal quantum efficiency was experimentally obtained for our structure with semi-bulk InGaN buffer and InGaN barrier in MQW. This improvement in IQE is the motivation for future work to realize LEDs with emission wavelength in the "green-gap" range using the semi-bulk buffer technique.

\section{References}

[1] E.F. Schubert, Light-Emitting Diodes, 2006.

[2] Y. Jiang, Y. Li, Y. Li, Z. Deng, T. Lu, Z. Ma, P. Zuo, L. Dai, L. Wang, H. Jia, W. Wang, J. Zhou, W. Liu, H. Chen, Realization of high-luminous-efficiency InGaN light-emitting diodes in the "green gap" range, Sci. Rep. 5 (2015) 10883.

[3] T. Wunderer, M. Feneberg, F. Lipski, J. Wang, R. a. R. Leute, S. Schwaiger, K. Thonke, a. Chuvilin, U. Kaiser, S. Metzner, F. Bertram, J. Christen, G.J. Beirne, M. Jetter, P. Michler, L. Schade, C. Vierheilig, U.T. Schwarz, a. D. Dräger, a. Hangleiter, F. Scholz, Three-dimensional GaN for semipolar light emitters, Phys. Status Solidi. 248 (2011) 549-560.

[4] L. Zhang, K. Cheng, H. Liang, R. Lieten, M. Leys, G. Borghs, Photoluminescence studies of polarization effects in InGaN/(In)GaN multiple quantum well structures, Jpn. J. Appl. Phys. 51 (2012) 3-6..

[5] P. de Mierry, L. Kappei, F. Tendille, P. Vennéguès, M. Leroux, J. Zuniga-Perez, Green emission from semipolar InGaN quantum wells grown on low-defect $\left(112^{-} 2\right) \mathrm{GaN}$ templates fabricated on patterned $r$-sapphire, Phys. Status Solidi. 253 (2016) $105-111$.

[6] S.C. Ling, T.C. Lu, S.P. Chang, J.R. Chen, H.C. Kuo, S.C. Wang, Low efficiency droop in blue-green m-plane InGaN/GaN light emitting diodes, Appl. Phys. Lett. 96 (2010) 29-32.

[7] F. Scholz, T. Wunderer, M. Feneberg, K. Thonke, A. Chuvilin, U. Kaiser, S. Metzner, F. Bertram, J. Christen, GaInN-based LED structures on selectively grown semi-polar crystal facets, Phys. Status Solidi. 207 (2010) 1407-1413.

[8] J. Park, Y. Kawakami, Photoluminescence property of InGaN single quantum well with embedded AlGaN $\delta$ layer, Appl. Phys. Lett. 88 (2006)

[9] S.H. Park, J. Park, E. Yoon, Optical gain in InGaN/GaN quantum well structures with embedded AlGaN ?? layer, Appl. Phys. Lett. 90 (2007) 
[10] H. Zhao, G. Liu, N. Tansu, Analysis of InGaN-delta-InN quantum wells for light-emitting diodes, Appl. Phys. Lett. 97 (2010) 2010-2013.

[11] S. Che, A. Yuki, H. Watanabe, Y. Ishitani, A. Yoshikawa, Fabrication of asymmetric GaN/InN/InGaN/GaN quantum-well light emitting diodes for reducing the quantum-confined stark effect in the blue-green region, Appl. Phys. Express. 2 (2009).

[12] H. Zhao, G. Liu, X.H. Li, G.S. Huang, J.D. Poplawsky, S.T. Penn, V. Dierolf, N. Tansu, Growths of staggered InGaN quantum wells light-emitting diodes emitting at 520-525 nm employing graded growth-temperature profile, Appl. Phys. Lett. 95 (2009).

[13] H. Zhao, G. Liu, J. Zhang, J.D. Poplawsky, V. Dierolf, N. Tansu, Approaches for high internal quantum efficiency green InGaN light-emitting diodes with large overlap quantum wells., Opt. Express. 19 Suppl 4 (2011) A991-A1007.

[14] C.T. Liao, M.C. Tsai, B.T. Liou, S.H. Yen, Y.K. Kuo, Improvement in output power of a $460 \mathrm{~nm}$ InGaN light-emitting diode using staggered quantum well, J. Appl. Phys. 108 (2010).

[15] H. Zhao, R.A. Arif, N. Tansu, A. Staggered, Design Analysis of Staggered InGaN Quantum Wells Light-Emitting Diodes at $500-540 \mathrm{~nm}, 15$ (2009) 1104-1114.

[16] C.Y. Chang, H. Li, T.C. Lu, High efficiency InGaN/GaN light emitting diodes with asymmetric triangular multiple quantum wells, Appl. Phys. Lett. 104 (2014) 1-6.

[17] M. Feneberg, K. Thonke, Polarization fields of III-nitrides grown in different crystal orientations, J. Phys. Condens. Matter. 19 (2007) 403201.

[18] Z. Yang, R. Li, Q. Wei, T. Yu, Y. Zhang, W. Chen, X. Hu, Analysis of optical gain property in the InGaN/GaN triangular shaped quantum well under the piezoelectric field, Appl. Phys. Lett. 94 (2009) 1-4.

[19] M.F. Schubert, J. Xu, J.K. Kim, E.F. Schubert, M.H. Kim, S. Yoon, S.M. Lee, C. Sone, T. Sakong, Y. Park, Polarizationmatched GaInNAlGaInN multi-quantum-well light-emitting diodes with reduced efficiency droop, Appl. Phys. Lett. 93 (2008) $3-5$.

[20] Y.K. Kuo, J.Y. Chang, M.C. Tsai, S.H. Yen, Advantages of blue InGaN multiple-quantum well light-emitting diodes with InGaN barriers, Appl. Phys. Lett. 95 (2009).

[21] Z. Lin, H. Wang, Y. Lin, M. Yang, Influence of In content in InGaN barriers on crystalline quality and carrier transport of GaN-based light-emitting diodes, J. Phys. D. Appl. Phys. 115112 (n.d.) 115112.

[22] A. Yuki, H. Watanabe, S.B. Che, Y. Ishitani, A. Yoshikawa, 1-2 ML thick InN-based quantum wells with InGaN barriers for blue-green light emitters, Phys. Status Solidi Curr. Top. Solid State Phys. 6 (2009) 417-420.

[23] M.J. Davies, P. Dawson, F.C. Massabuau, A. Le Fol, R.A. Oliver, M.J. Kappers, C.J. Humphreys, A study of the inclusion of prelayers in InGaN / GaN single- and multiple-quantum-well structures, 872 (2015) 866-872.

[24] T. Li, Q.Y. Wei, A.M. Fischer, J.Y. Huang, Y.U. Huang, F.A. Ponce, J.P. Liu, Z. Lochner, J. Ryou, The effect of InGaN underlayers on the electronic and optical properties of InGaN / GaN quantum wells The effect of InGaN underlayers on the electronic and optical properties of InGaN / GaN quantum wells, 41115 (2013) 1-5.

[25] D.M. Van Den Broeck, D. Bharrat, a. M. Hosalli, N. a. El-Masry, S.M. Bedair, Strain-balanced InGaN/GaN multiple quantum wells, Appl. Phys. Lett. 105 (2014) 31107.

[26] V. Ramesh, a. Kikuchi, K. Kishino, M. Funato, Y. Kawakami, Strain relaxation effect by nanotexturing InGaN/GaN multiple quantum well, J. Appl. Phys. 107 (2010).

[27] S.-H. Park, Light emission characteristics of blue strain-compensated InGaN/InGaN/InGaN light-emitting diodes, J. Korean Phys. Soc. 66 (2015) 277-281.

[28] J. Zhang, N. Tansu, Improvement in spontaneous emission rates for InGaN quantum wells on ternary InGaN substrate for lightemitting diodes, J. Appl. Phys. 110 (2011) 2-7.

[29] K. Lekhal, B. Damilano, H.T. Ngo, D. Rosales, P. De Mierry, S. Hussain, P. Vennéguès, B. Gil, Strain-compensated ( Ga , In ) $\mathrm{N} /(\mathrm{Al}, \mathrm{Ga}) \mathrm{N} / \mathrm{GaN}$ multiple quantum wells for improved yellow / amber light emission, 142101 (2015) 1-6.

[30] T. Huong, B. Gil, B. Damilano, K. Lekhal, P. De Mierry, Superlattices and Microstructures Internal quantum ef fi ciency and Auger recombination in green, yellow and red InGaN-based light emitters grown along the polar direction, Superlattices Microstruct. 103 (2017) 245-251..

[31] D. Zhu, A.N. Noemaun, M.F. Schubert, J. Cho, E.F. Schubert, M.H. Crawford, D.D. Koleske, Enhanced electron capture and symmetrized carrier distribution in GaInN light-emitting diodes having tailored barrier doping, Appl. Phys. Lett. 96 (2010) 1-4. 


\section{ACCEPTED MANNUSCRIPT}

[32] K. Pantzas, Y. El Gmili, J. Dickerson, S. Gautier, L. Largeau, O. Mauguin, G. Patriarche, S. Suresh, T. Moudakir, C. Bishop, a. Ahaitouf, T. Rivera, C. Tanguy, P.L. Voss, a. Ougazzaden, Semibulk InGaN: A novel approach for thick, single phase, epitaxial InGaN layers grown by MOVPE, J. Cryst. Growth. 370 (2013) 57-62.

[33] S. Gautier, C. Sartel, S. Ould-Saad, J. Martin, A. Sirenko, A. Ougazzaden, GaN materials growth by MOVPE in a new-design reactor using DMHy and NH3, J. Cryst. Growth. 298 (2007) 428-432.

[34] Y. El Gmili, G. Orsal, K. Pantzas, T. Moudakir, S. Sundaram, G. Patriarche, J. Hester, a. Ahaitouf, J.P. Salvestrini, a. Ougazzaden, Multilayered InGaN/GaN structure vs. single InGaN layer for solar cell applications: A comparative study, Acta Mater. 61 (2013) 6587-6596.

[35] D.S. Software, Atlas User's Manual, (2014) 567-1000.

[36] F. Bernardini, V. Fiorentini, D. Vanderbilt, Spontaneous polarization and piezoelectric constants of III-V nitrides, 56 (1997) 4.

[37] N. Nanhui, W. Huaibing, L. Jianping, L. Naixin, X. Yanhui, H. Jun, D. Jun, S. Guangdi, Improved quality of InGaN/GaN multiple quantum wells by a strain relief layer, J. Cryst. Growth. 286 (2006) 209-212.

[38] J.-H. Yang, L. Shi, L.-W. Wang, S.-H. Wei, Non-Radiative Carrier Recombination Enhanced by Two-Level Process: A FirstPrinciples Study, Sci. Rep. 6 (2016) 21712.

[39] Y.-L. Lai, C.-P. Liu, Y.-H. Lin, T.-H. Hsueh, R.-M. Lin, D.-Y. Lyu, Z.-X. Peng, T.-Y. Lin, Origins of efficient green light emission in phase-separated InGaN quantum wells, Nanotechnology. 17 (2006) 3734.

[40] Z. Lin, H. Wang, Y. Lin, M. Yang, W. Wang, G. Li, Influence of In content in InGaN barriers on crystalline quality and carrier transport of GaN-based light-emitting diodes, J. Phys. D. Appl. Phys. 49 (2016) 115112. 